The Skin of the Film 



\section{The Skin of the Film}

Intercultural Cinema, Embodiment, and the Senses LAURA U. MARKS

DUKE UNIVERSITY PRESS Durham and London 2000

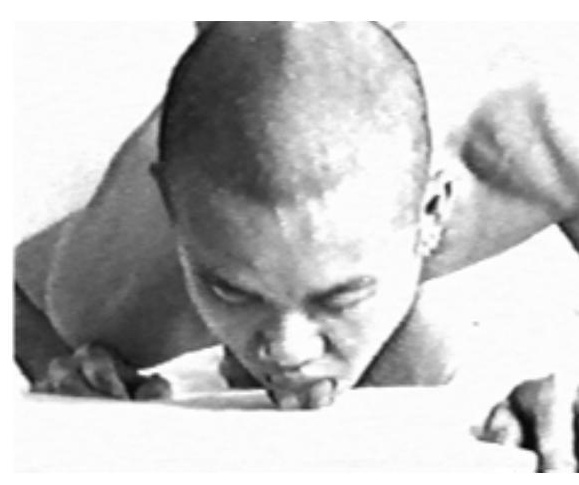


(c) 2000 Duke University Press

All rights reserved

Printed in the United States of

America on acid-free paper @

Designed by C. H. Westmoreland

Typeset in Melior with DIN Neuzeit

Grotesk Bold Condensed display

by Tseng Information Systems, Inc.

Library of Congress Cataloging-in-

Publication Data appear on the

last printed page of this book.

Title page art: Still from Sniff 